\title{
Recovery of Physiological Variables and Performance and the Relationship between Training load and Psychological State for a Recreational Runner during Marathon Season: a Case Study*
}

\author{
Fuminori Takayama ${ }^{1,2}$, Wataru Shimazu ${ }^{3}$, Atsushi Aoyagi ${ }^{4}$, and Yoshiharu Nabekura ${ }^{1}$ \\ ${ }^{1}$ Faculty of Health and Sport Sciences, University of Tsukuba \\ 1-1-1 Tennodai, Tsukuba-shi, Ibaraki 305-8574, Japan \\ E-mail: fuminori.takayama1990@gmail.com \\ ${ }^{2}$ Research Fellow of Japan Society for the Promotion of Science \\ 5-3-1 Kojimachi, Chiyoda-ku, Tokyo 102-0083, Japan \\ ${ }^{3}$ Nagoya Junior \& Senior High School \\ 2-1-58 Sunadabashi, Higashi-ku, Nagoya, Aichi 461-8676, Japan \\ ${ }^{4}$ Graduate School of Comprehensive Human Sciences, University of Tsukuba \\ 1-1-1 Tennodai, Tsukuba-shi, Ibaraki 305-8574, Japan \\ *Original article published in Japan J. Phys. Educ. Hlth. Sport Sci. 63: 383-395, 2018 (in Japanese) \\ [Received September 6, 2018; Accepted December 17, 2018; Published online January 15, 2019]
}

\begin{abstract}
Some recreational runners participate in consecutive races within a short period. A high frequency of participation may not allow for sufficient recovery time, leading to overreaching. This case study reports on the training load, physiological variables, performance, and psychological state of a male recreational runner during a 16 -week marathon season. The runner completed four marathon races over a period of eight weeks. Training load was quantified based on the cumulative time spent in three intensity zones (zone 1:< the ventilatory threshold; zone 2: between the ventilatory threshold and respiratory compensation point; zone 3: $>$ the respiratory compensation point) using heart rate monitoring. The Hooper questionnaire was completed every morning to quantify sleep, stress, fatigue, and muscle soreness. The runner performed four identical treadmill running tests throughout the season. The coefficient of variation for maximal velocity and the physiological variables was $1.0 \%$ and $1.8 \%-5.2 \%$, respectively. Pearson correlation showed significant relationships between training load and stress, fatigue, and muscle soreness. There was no significant relationship between training load and sleep. In conclusion, it appeared that the subject runner was able to complete four marathon races without overreaching. These findings suggest that the training load and Hooper questionnaire are practical tools for monitoring recreational runners during the marathon season.
\end{abstract}

Keywords: running economy, maximal oxygen uptake, anaerobic threshold

\section{Introduction}

The marathon is an endurance sport that imposes a heavy load on the systemic organs of the runner. Heart rate (HR) during a marathon race reaches 80 $\%-90 \%$ of maximal HR (HRmax) (Billat et al., 2012), and cardiac function declines after the race (Neilan et al., 2006). Studies have shown that marathon running also causes muscle damage (Kobayashi et al., 2005; Takayama et al., 2016a, 2017b, Tojima et al., 2016).

Some runners participate in consecutive races within a short period of time. A high frequency of participation may not allow for sufficient recovery time, leading to overreaching. Overreaching refers to an accumulation of training and/or non-training stress that leads to a short-term performance decrement (Coutts et al., 2007b). Aubry et al. (2014) evaluated cycling performance after one week of moderate training and after three weeks of overload 
training and a four-week tapering period for 23 male triathletes. The study reported that the degree of performance improvement following the tapering period was lower in the subjects who had experienced overreaching after overload training in comparison to those who had not. This result suggests that overreaching may interfere with training adaptation.

Findings regarding the relationship between training and competition load (Training Load: TL) and recovery state are valuable for runners seeking to optimize performance while avoiding overreaching. Importantly, it has been established that psychological state is also reflected in TL (Auersperger et al., 2014; Buchheit et al., 2013; Coutts et al., 2007a, 2007b; Faude et al., 2011; Moalla et al., 2016; Nunes et al., 2014) and that it is related to changes in performance (Buchheit et al., 2013; Coutts et al., 2007a, 2007b; Faude et al., 2011). Coutts et al. (2007b) measured the TL, psychological state, and time-trial running of 16 triathletes before and after four weeks of overload training and after a twoweek tapering period. They reported that the recovery-stress state and time-trial performance of the athletes were impaired immediately after the overload training period. On the other hand, the psychological state and time-trial performance of the athletes improved after the tapering period. These results highlight the importance of regularly monitoring psychological state and performance.

In previous studies investigating recovery after running a marathon, maximal velocity (Vmax) or time to exhaustion during a treadmill running test have been used as performance variables (Armstrong et al., 2015; Hottenrott et al., 2016; Takayama et al., 2016a, 2017a, 2017b; Zouhal et al., 2006) based on the significant correlation between marathon race time and these two measures (Noakes et al., 1990). Physiological variables having a significant correlation with marathon race time, such as maximal oxygen uptake ( $\left.\dot{\mathrm{V}}_{2} \mathrm{max}\right)$, anaerobic threshold (AT), and running economy (RE), have also been used as performance variables (Hottenrott et al., 2016; Kyröläinen et al., 2000; Takayama et al., 2016a, 2017a, 2017b; Zouhal et al., 2006). A number of these studies have shown that a marathon run temporarily reduces performance and certain physiological variables but that these variables recover within one week after a race regardless of any differences in the proficiency levels of the participating runners. For example, $\dot{\mathrm{V}}_{2} \max$ and Vmax returned to pre-race levels within three days of a marathon run for both novice runners (Takayama et al., 2017b) and national-level runners (Zouhal et al., 2006). However, these previous studies evaluated recovery from only a single race; it is not clear whether the recreational runner who participates in consecutive races within a short period can recover in similar fashion.

In this case study, we quantified $\mathrm{TL}, \dot{\mathrm{V}} \mathrm{O}_{2} \max$, AT, RE, performance, and psychological state for a runner who completed four marathon races in a period of eight weeks. The purpose of the study was (1) to show the runner's recovery in terms of three common physiological variables and performance and (2) to investigate the relationship between the runner's TL and his psychological state.

\section{Methods}

\subsection{Subject and experimental design}

The subject of the study was a male graduate student runner (age: 24 years; height: $181 \mathrm{~cm}$; body weight: $68 \mathrm{~kg}$; running experience: 11 years; previous marathon race experience: two races). As an undergraduate, the subject belonged to his university's track and field club, running middle and long distances. As a graduate student, he continued running recreationally. The subject's best times were recorded during his college years: $800 \mathrm{~m}: 1 \mathrm{~min} 53 \mathrm{sec}$; $1500 \mathrm{~m}: 3 \mathrm{~min} 51 \mathrm{sec} ; 5000 \mathrm{~m}: 14 \mathrm{~min} 55 \mathrm{sec} ; 10,000$ $\mathrm{m}: 31 \mathrm{~min} 05 \mathrm{sec}$. The subject runner had not run either a marathon or a half-marathon before graduating from university. Prior to the start of the experimental period, the subject's best half-marathon time was $1 \mathrm{~h} 9 \min 57 \mathrm{sec}$; his best marathon time was $2 \mathrm{~h} 38 \mathrm{~min} 59 \mathrm{sec}$. He had run a marathon in the Japan Championships in Athletics. The runner was fully informed of the purpose, method, and potential risks of the present study and agreed to participate. The present study was approved by the Ethics Committee of the University of Tsukuba.

We set the 16-week period from August to December in 2016 as the experimental period (Figure 1). The runner's TL and psychological state were quantified throughout this period. The runner completed four marathon races in a span of eight weeks (in weeks $6,8,12$, and 14 of the experimental period). A treadmill running test was conducted in 


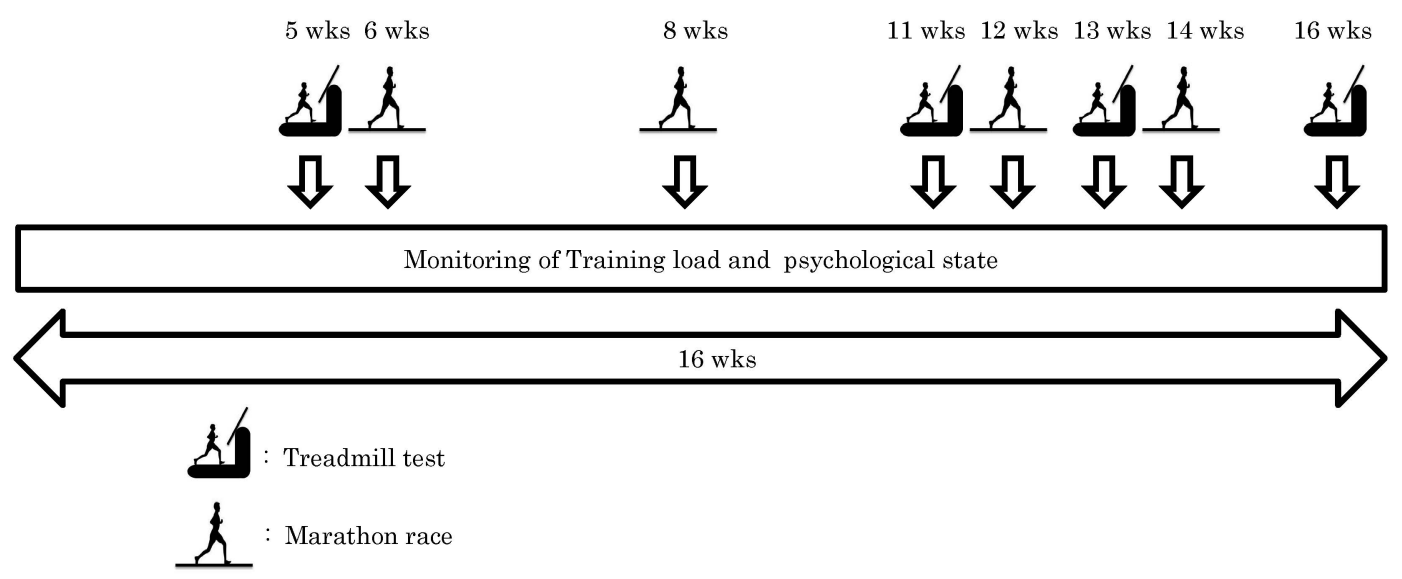

Figure 1 Experimental design.

the fifth week (nine days before the first marathon race), the eleventh week (seven days before the third marathon race), the thirteenth week (seven days after the third marathon race), and the sixteenth week (ten days after the fourth marathon race). It should be noted that the runner committed to doing his best in all of his races.

\subsection{Treadmill running test}

Before the treadmill running test, body weight was measured (TBF-102, Tanita, Japan). The test was performed on a motorized treadmill (ORK-7000, Ohtake Root Kogyo, Japan) set at a $1 \%$ gradient. The temperature of the experimental room was controlled within a range of 22 to $24^{\circ} \mathrm{C}$. All measurements were taken at 10 am to avoid diurnal variation.

The treadmill running test consisted of a submaximal test and a maximal test. The submaximal test was conducted first to quantify the RE. The velocity of the submaximal test was $13.5 \mathrm{~km} / \mathrm{h}$, which corresponded to $85 \%$ of the velocity of pace of the best marathon time on the basis of a previous study (Takayama et al., 2017a). Following a five-minute recovery period after the submaximal test, the maximal test was conducted. This test was initiated with a velocity of $8.4 \mathrm{~km} / \mathrm{h}$; velocity was then increased by $0.6 \mathrm{~km} / \mathrm{h}$ per minute until volitional exhaustion.

Using the computerized standard open circuit technique (AE-310s, Minato Medical Science, Japan), expired gas analysis was continuously performed to measure oxygen consumption $\left(\mathrm{V}_{2}\right)$, carbon dioxide production $\left.(\dot{\mathrm{V} C O})_{2}\right)$, ventilation $\left(\dot{\mathrm{V}}_{\mathrm{E}}\right)$, and the respiratory exchange ratio (RER). The gas analysis data were converted into 20-second time-binned mean values. Before each treadmill running test, calibration was conducted by using calibration gas and a calibration syringe. HR was measured by HR monitor (M400, Polar electro, Finland). The rating of perceived exertion (RPE) was measured at the end of the maximal test using the Borg scale (Borg, 1973), which was translated into Japanese by Onodera and Miyashita (1976).

$\dot{\mathrm{V}} \mathrm{O}_{2}$, energy cost (EC), and HR during the submaximal test were analyzed. Ventilatory threshold (VT), respiratory compensation point (RCP), the threshold at which RER exceeds 1.0 (RER1.0), $\dot{\mathrm{V}}_{2}$ max, HRmax, and Vmax during the maximal test were analyzed. VT, RCP, and RER1.0 were expressed as $\% \dot{\mathrm{VO}}_{2}$ max and velocity (vVT, vRCP, vRER1.0). The data on expired gas and HR during the submaximal test were analyzed based on the last one-minute value. EC was calculated from $\dot{\mathrm{VO}}_{2}$ and RER (Fletcher et al., 2009). On the basis of the Vslope method, VT and RCP were quantified using $\dot{\mathrm{V}} \mathrm{O}_{2} / \dot{\mathrm{V} C O} \mathrm{C}_{2}$ and $\dot{\mathrm{V}}_{\mathrm{E}} / \dot{\mathrm{V} C O} \mathrm{C}_{2}$ plots, respectively (Beaver et al., 1986; Lourenço et al., 2011). RER1.0 was defined as the point at which RER stabilized above 1.0 (Solberg et al., 2005). $\mathrm{VO}_{2} \max$ was confirmed according to the following four criteria: (1) a leveling-off of $\dot{\mathrm{VO}}_{2} \quad(<150 \mathrm{ml} / \mathrm{min})$, (2) HRmax $\geq 100 \%$ of the subject's age-predicted HRmax (i.e., 220-age), maximal RER $\geq 1.1$, and (4) RER $\geq 19$. Vmax was determined by the last stage of the maximal test. When the subject was unable to complete a full 60 seconds at the current velocity, Vmax was determined by adding a fraction of the final velocity to the velocity in the immediately preceding 60 seconds. 


\subsection{Training load}

The runner performed while wearing an HR monitor (M400, Polar electro, Finland). TL was quantified based on HR at VT and RCP in the treadmill running test (zone 1: $<\mathrm{VT}$, zone 2: between VT and RCP, zone 3:> RCP) (Lucía et al., 2000; Muñoz et al., 2014; Neal et al., 2011). Since the HR value at VT and RCP in trained endurance athletes is stable over a season (Lucía et al., 2000), we used the first treadmill running test result to determine the intensity boundaries (zone 1: $<171$ beats/min; zone 2 : 171-182 beats/min; zone $3: \geqq 183$ beats $/ \mathrm{min})$. TL was calculated based on the time-in-zone method (Sylta et al., 2014). The score for each zone was computed by multiplying the accumulated duration (minutes) in the zone by an intensity-weighted multiplier ( 1 for zone 1, 2 for zone 2, and 3 for zone 3 ) and summing the three zone scores. Running time in each zone was calculated, and the ratio of each of these values to total running time was computed.

\subsection{Psychological state}

Psychological state was assessed using the Hooper questionnaire (Hooper et al., 1995). The Hooper questionnaire consists of four items: (1) sleep, (2) stress, (3) fatigue, (4) muscle soreness. The respondent is asked to rate each variable on a seven-point scale (with 1 representing "very very good" and 7 representing "very very bad"). The overall score (Hooper's score) is determined by summing the four scores. The subject runner filled out the questionnaire every morning after awakening.

\subsection{Statistical analysis}

Data are summarized using the mean \pm standard deviation and coefficient of variation (CV). For TL and psychological state, weekly analysis was conducted. The training intensity distribution of each period was analyzed using weeks 1 through 5 as the preparation period (Phase 1), weeks 6 through 14 as the race period (Phase 2), and weeks 15 and 16 as the recovery phase (Phase 3). During the race period, analyses including and excluding the marathon races were conducted. The relationship between the subject's daily TL and his psychological state the next day was analyzed using Pearson correlation analysis (Bouchheit et al., 2013). Here, the correlation between TL excluding the day of the marathon races and the subject's psychological state was also analyzed. The correlation was ranked as trivial $(<0.1)$, small $(0.1-0.29)$, moderate (0.3-0.49), large (0.5-0.69), very large (0.7-0.89), and almost perfect $(0.9-1.0)$ on the basis of Hopkins et al. (2009).

\section{Results}

The subject completed all four marathon races (week 6: 2 h 38 min; week 8: 2 h $47 \mathrm{~min}$; week 12: 2 h 36 min; week 14: 2 h 44 min).

\subsection{Training load}

Weekly running duration during the experimental period was $277 \pm 130 \mathrm{~min}$ (CV: 46.9\%), while weekly TL values were $381 \pm 179$ arbitrary units (AU) (CV: 46.9\%) (Figure 2). The training intensity times in zones 1,2 , and 3 were $73 \pm 16 \%(\mathrm{CV}$ : $22.6 \%$ ), $14 \pm 15 \%$ (CV: $108.2 \%$ ), and $13 \pm 11 \%$ (CV: $83.0 \%$ ), respectively. Figure 3 shows the training intensity distribution for each phase in both relative (\%) and absolute (minutes) terms. For Phase 1 , the training distribution shows that the runner's training intensity was in zone $179 \%$ (238 min) of the time, in zone $211 \%$ ( $32 \mathrm{~min}$ ) of the time, and in zone $310 \%$ (27 min) of the time. For Phase 2, when the marathon races are included, the training distribution shows $70 \%$ (213 min) in zone 1, 18\% (57 $\mathrm{min}$ ) in zone 2 , and $12 \%(36 \mathrm{~min})$ in zone 3 . When the marathon races are excluded, the distribution shows $89 \%$ (206 $\mathrm{min})$ of the runner's training time in zone $1,4 \%(9 \mathrm{~min})$ in zone 2 , and $7 \%(18 \mathrm{~min})$ in zone 3. For Phase 3, the distribution shows $72 \%$ (76 $\mathrm{min}$ ) in zone $1,4 \%$ (5 min) in zone 2 , and $24 \%$ (19 $\mathrm{min}$ ) in zone 3 . The weekly running distance was 59 $\pm 27 \mathrm{~km}$.

\subsection{Treadmill running test}

Table 1 gives the results of the treadmill running test. Vmax was the lowest, at $20.6 \mathrm{~km} / \mathrm{h}$, in the first measurement and ranged from 20.8 to $21.0 \mathrm{~km} / \mathrm{h}$ thereafter. The CV for Vmax throughout the four measurements was $1.0 \%$. The CV for the physiological variables ranged from $1.8 \%$ to $5.2 \%$. 


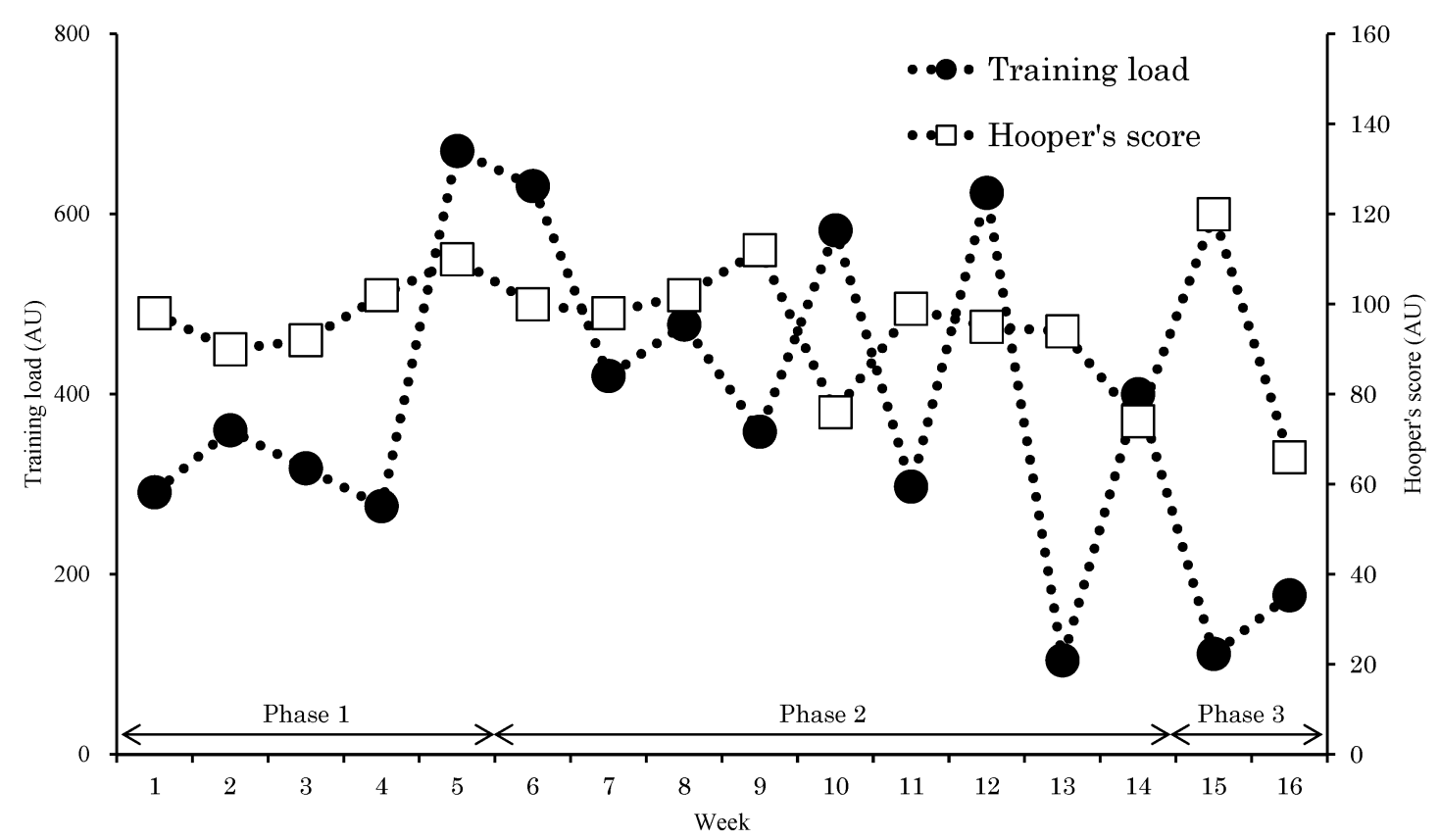

Figure 2 Weekly basis analyses of Training load and Hooper's score. Training load includes the marathon races.
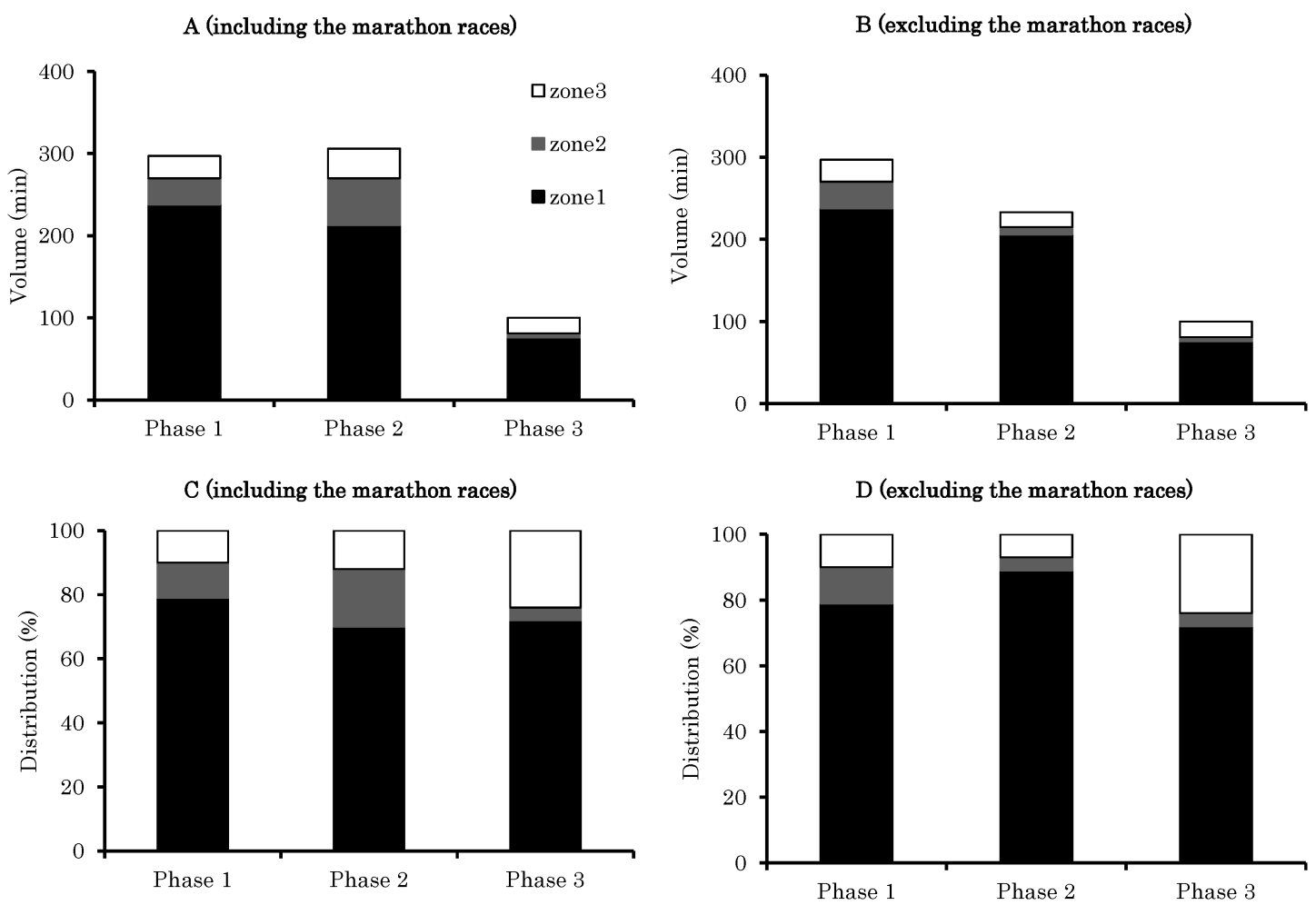

Figure 3 Weekly absolute (A, B) and relative (C, D) running duration. $\mathrm{A}$ and $\mathrm{C}$ are calculated by including the marathon races. $\mathrm{B}$ and $\mathrm{D}$ are calculated by excluding the marathon races. 


\subsection{Psychological state}

The results of the psychological state per week were as follows: sleep: $25.6 \pm 3.9 \mathrm{AU}(\mathrm{CV}: 15.3 \%)$; stress: $24.3 \pm 4.3 \mathrm{AU}$ (CV: $17.8 \%$ ); fatigue: $27.0 \pm$ 5.0 AU (CV: 18.6\%); muscle soreness: $18.6 \pm 6.3$ AU (CV: $33.7 \%)$. The overall Hooper's score was 95.5 \pm 14.1 AU (CV: 14.7\%) (Figure 2).

Table 1 Results of the treadmill test.

\begin{tabular}{|c|c|c|c|c|c|c|}
\hline & $1^{\text {st }}$ & $2^{\text {nd }}$ & $3^{\text {rd }}$ & $4^{\text {th }}$ & Mean \pm SD & $(\mathrm{CV})$ \\
\hline$\dot{\mathrm{V}} \mathrm{O}_{2}(\mathrm{ml} / \mathrm{kg} / \mathrm{min})$ & 43.7 & 45.5 & 44.9 & 46.8 & $45.2=$ & $(2.9$ \\
\hline$/ \mathrm{kg} / \mathrm{km})$ & .94 & 0.97 & 0.95 & 1.00 & 0.97 & (2. \\
\hline HR & 57 & 161 & 160 & 164 & 16 & (1.8) \\
\hline$\left.{ }_{2} \max \right)$ & 72.0 & 79.0 & 74.5 & 72.9 & 74.6 & $(4.2)$ \\
\hline $\mathrm{RCP}\left(\% \dot{\mathrm{V}} \mathrm{O}_{2} \max \right)$ & 85.3 & 94.1 & 91.8 & 92.7 & $90.9 \pm$ & (4.3) \\
\hline RER1.0 (\% $\dot{\mathrm{V}}_{2} \mathrm{ma}$ & 86.9 & 94.4 & 94.6 & 91.2 & $91.8 \pm$ & $(4.0)$ \\
\hline vVT & 15.6 & 17.4 & 16.2 & 15.6 & 16 & $(5.2)$ \\
\hline & 18.0 & 19.2 & 19.2 & 19.2 & 18. & (3.2) \\
\hline vRER1.0 & 18.6 & 19.8 & 19.2 & 19.2 & $19.2 \pm 0.5$ & (2.6) \\
\hline & 67.8 & 69.6 & 69.1 & 75.2 & 70.4 & (4.6) \\
\hline $\mathrm{HRn}$ & 199 & 206 & 202 & 212 & 205 & (2.7) \\
\hline $\operatorname{Vmax}(\mathrm{km} / \mathrm{h})$ & 20.6 & 21.0 & 20.8 & 21.0 & $20.8 \pm 0.2$ & $(1.0)$ \\
\hline
\end{tabular}

\subsection{Relationship between training load and psy- chological state}

When including the marathon races, no significant correlation was observed between TL and sleep $(r=-.003, p=.971)$. On the other hand, a significant correlation was observed between TL and stress $(\mathrm{r}=.207, \mathrm{p}=.030)$, fatigue $(\mathrm{r}=.540, \mathrm{p}$ $<.001)$, muscle soreness $(\mathrm{r}=.448, \mathrm{p}<.001)$, and Hooper's score $(r=.446, p<.001)$.

When excluding the marathon races, no significant correlation was observed between TL and sleep $(\mathrm{r}=-.056, \mathrm{p}=.570)$ and stress $(\mathrm{r}=.124$, $\mathrm{p}=.206$ ). On the other hand, a significant correlation was observed between TL and fatigue $(r=.473$, $\mathrm{p}<.001)$, muscle soreness $(\mathrm{r}=.210, \mathrm{p}=.031)$, and Hooper's score $(r=.282, p=.003)$.

There were remarkable differences in the magnitudes of the correlation coefficients for fatigue, muscle soreness, and Hooper's score when we compared the results of including and excluding the marathon races. When including the marathon races, a large correlation coefficient was observed

Table 2 Training load and psychological state for seven days after each marathon race.

\begin{tabular}{|c|c|c|c|c|c|c|c|c|}
\hline & & 1 days & 2 days & 3 days & 4 days & 5 days & 6 days & 7 days \\
\hline \multirow{6}{*}{$\begin{array}{l}\text { Marathon } \\
\text { race } 1\end{array}$} & \multirow{6}{*}{$\begin{array}{l}\text { Training load (AU) } \\
\text { Sleep (AU) } \\
\text { Stress (AU) } \\
\text { Fatigue (AU) } \\
\text { Muscle soreness (AU) } \\
\text { Hooper's score (AU) }\end{array}$} & 0 & 0 & 85 & 49 & 84 & 15 & 188 \\
\hline & & 4 & 2 & 2 & 5 & 3 & 5 & 2 \\
\hline & & 5 & 4 & 3 & 3 & 2 & 2 & 2 \\
\hline & & 6 & 5 & 3 & 4 & 5 & 3 & 2 \\
\hline & & 7 & 6 & 4 & 3 & 2 & 2 & 2 \\
\hline & & 22 & 17 & 12 & 15 & 12 & 12 & 8 \\
\hline \multirow{6}{*}{$\begin{array}{l}\text { Marathon } \\
\text { race } 2\end{array}$} & \multirow{6}{*}{$\begin{array}{l}\text { Training load (AU) } \\
\text { Sleep (AU) } \\
\text { Stress (AU) } \\
\text { Fatigue (AU) } \\
\text { Muscle soreness (AU) } \\
\text { Hooper's score (AU) }\end{array}$} & 0 & 0 & 49 & 61 & 0 & 248 & 0 \\
\hline & & 1 & 4 & 5 & 7 & 2 & 6 & 4 \\
\hline & & 3 & 3 & 5 & 6 & 2 & 5 & 5 \\
\hline & & 6 & 5 & 6 & 6 & 4 & 4 & 7 \\
\hline & & 5 & 3 & 2 & 2 & 1 & 1 & 2 \\
\hline & & 15 & 15 & 18 & 21 & 9 & 16 & 18 \\
\hline \multirow{6}{*}{$\begin{array}{l}\text { Marathon } \\
\text { race } 3\end{array}$} & \multirow{6}{*}{$\begin{array}{l}\text { Training load (AU) } \\
\text { Sleep (AU) } \\
\text { Stress (AU) } \\
\text { Fatigue (AU) } \\
\text { Muscle soreness (AU) } \\
\text { Hooper's score (AU) }\end{array}$} & 0 & 0 & 0 & 0 & 32 & 31 & 42 \\
\hline & & 6 & 2 & 1 & 5 & 2 & 6 & 3 \\
\hline & & 5 & 4 & 3 & 3 & 2 & 3 & 2 \\
\hline & & 7 & 5 & 3 & 2 & 2 & 3 & 2 \\
\hline & & 7 & 5 & 4 & 2 & 2 & 2 & 1 \\
\hline & & 25 & 16 & 11 & 12 & 8 & 14 & 8 \\
\hline \multirow{6}{*}{$\begin{array}{l}\text { Marathon } \\
\text { race } 4\end{array}$} & \multirow{6}{*}{$\begin{array}{l}\text { Training load (AU) } \\
\text { Sleep (AU) } \\
\text { Stress (AU) } \\
\text { Fatigue (AU) } \\
\text { Muscle soreness (AU) } \\
\text { Hooper's score (AU) }\end{array}$} & 0 & 0 & 0 & 39 & 73 & 0 & 0 \\
\hline & & 5 & 6 & 5 & 7 & 4 & 1 & 5 \\
\hline & & 5 & 6 & 6 & 5 & 3 & 3 & 3 \\
\hline & & 7 & 7 & 5 & 4 & 2 & 5 & 4 \\
\hline & & 7 & 5 & 3 & 2 & 2 & 2 & 1 \\
\hline & & 24 & 24 & 19 & 18 & 11 & 11 & 13 \\
\hline
\end{tabular}

The gray area indicates that the value is higher than the 16-week average value (Training load: 54.4 A.U., Sleep: 3.7 A.U., Stress: 3.5 A.U., Fatigue: 3.9 A.U., Muscle soreness: 2.7 A.U., Hooper's score: 13.9 A.U.). 
between TL and fatigue. However, the correlation was only moderate when we excluded the marathon races. In addition, the correlation between TL and muscle soreness and Hooper's score was moderate when the races were included, but small when the races were excluded. Figure 4 shows the significant relationship between TL and Hooper's score.

\subsection{Training load and psychological state from one to seven days after each marathon race}

Table 2 shows the TL and psychological state values from one to seven days after each marathon race. In cases where the value is higher than the average value per day throughout the experimental period (TL: 54.4 AU; sleep: 3.7 AU; stress: 3.5 AU; fatigue: 3.9 AU; muscle soreness: 2.7 AU; Hooper's score: $13.9 \mathrm{AU})$, the backgrounds are shown in gray.

\section{Discussion}

In this case study, the recovery of physiological variables and performance and the relationship between the TL and the psychological state of a runner who participated in consecutive marathon races within a short period of time were investigated. The main finding was that the variation in performance and in the monitored physiological variables was small. This result indicates that the subject in this study was able to complete four marathon races without overreaching. While there was a significant correlation between TL and stress, fatigue, and muscle soreness, no significant correlation was observed between TL and sleep. Study results suggest that TL and the Hooper questionnaire are practical monitoring tools for optimizing running performance.

Recovery is defined as the ability to meet or exceed pre-performance levels in a particular activity (Bishop et al., 2008). Armstrong et al. (2015) stated that Vmax, which is closely related to marathon time, is an excellent indicator of recovery following a marathon race. Saunders et al. (2010) conducted four treadmill tests within 17 weeks for 34 runners with slightly inferior performance to the performance of the runner in our study (average value of Vmax: $19.0 \mathrm{~km} / \mathrm{h}$ ) and reported that the variation of Vmax was $2.5 \%$. On the other hand, the CV for Vmax in our study was $1.0 \%$, indicating that per- formance was stable. In addition, the CV for our physiological variables ranged from $1.8 \%-5.2 \%$, which is similar or lower than the results in a previous study (Lourenço et al., 2011). Takayama et al. (2016a) conducted a treadmill running test for seven recreational college runners before their marathon race and two and 10 days afterwards. Results showed that $\mathrm{VO}_{2} \max , \mathrm{RE}$, and Vmax were reduced two days after the marathon race but recovered to pre-race levels 10 days after the race was run. Moreover, a previous study investigating the behavior of these same physiological variables and performance for 11 recreational runners showed that these variables returned to pre-race levels within seven days following the subjects' marathon race (Takayama et al., 2017a). In the present study, we conducted four treadmill running tests including seven and 10 days after the marathon races of our subject runner, who was participating in consecutive races within a short period of time. It was shown that the physiological variables and performance were recovered. In the present study, we conducted no treadmill running tests during the first six days after each of the subject's marathon races, as the test might increase the possibility of injury if performed at a time when muscle damage is likely to be most severe. It has been established that muscle damage temporarily reduces physiological variables and performance (Braun and Dutto, 2003; Marcora and Bosio, 2007). As shown in Table 2, muscle soreness one-to-two days after a marathon race was higher than the average value throughout the experimental period. Thus, the fact that the physiological variables and performance were relatively stable in the present study may have been influenced by the timing of the measurements after the races. In other words, if the treadmill test had been conducted sooner after the races, the CV values might have been higher.

The maximum difference in the four marathon times in the present study was 11 minutes. However, it is difficult to compare a runner's performance in different races using an absolute measure such as finish time since marathon times are influenced by many factors, both internal (e.g., pacing strategy, nutritional strategy) and external (e.g., topography and weather conditions). Indeed, the second and fourth marathon races in our study involved an undulating course and severe weather conditions. Using the treadmill running test to determine the 
recovery state based on physiological variables and performance allowed us control the influence of external factors. According to our results, even if a runner repeatedly participates in marathon races over a short period of time, the monitored variables showed recovery within seven to 10 days after race completion. This result is similar to results in our previous studies investigating these same variables for recreational runners running a marathon race (Takayama et al., 2016a, 2017a).

Athletes in team sports such as soccer, rugby, and basketball may participate in matches two or three times a week during a congested period. As with marathon runners after a race, decreases in muscle glycogen (Krustrup et al., 2011), decreases in maximal muscle strength and increases in creatine kinase activity (Nedelec et al., 2014) have been observed in players after a team sport match. Studies on the recovery of team sport athletes are welldeveloped (Twist and Highton, 2013), and there has been extensive research conducted on the relationship between TL and psychological state and performance for team sport athletes (Buchheit et al., 2013; Coutts et al., 2007a; Faude et al., 2011; Moalla et al., 2016; Nunes et al., 2014). Buchheit et al. (2013) measured the correlation between daily TL and psychological state, submaximal HR, postexercise HR variability, and salivary cortisol during the overload period for Australian football players. Their study showed a significant correlation between TL and psychological state and HR response. Based on this result, the authors of the study concluded that TL, submaximal HR, and psychological state are the best simple measures for monitoring training responses. In the present study, responses to the Hooper questionnaire were reflected in the daily TL of recreational runners, as there was a significant correlation between TL and stress, fatigue, muscle soreness, and Hooper's score when the marathon races were included in the test. On the other hand, no significant correlation was observed between TL and sleep, both when the races were included in the data and when they were not. It should be noted that sleep is influenced by factors other than TL, such as caffeine and alcohol consumption and the use of electronic floodlit media devices (Nedelec et al., 2015). Indeed, according to a 16-week study of professional soccer athletes by Moalla et al. (2016) that determined the correlation between TL and psychological state quantified by use of the Hooper questionnaire, the correlation coefficient was lowest between TL and sleep (sleep: $r=.23$; stress: $r=.30$; fatigue: $r=.48$; muscle soreness: $r=.48)$. Therefore, it is possible that nontraining factors affected sleep in our runner. It has been found that sleep is related to glycogen resynthesis, muscle damage, injury risk, and thus to recovery in athletes (Nédélec et al., 2015). A case study involving an elite triathlete who had experienced overreaching reported that the weekly value of sleep as quantified by the Hooper questionnaire gradually worsened (Plews et al., 2012). Based on these findings, it is essential to develop a balance between training and/or non-training load and recovery to optimize performance without overreaching. Especially for recreational runners, it is highly practical to use simple methods to evaluate the recovery state. Thus, quantifying both TL and psychological state using the Hooper questionnaire is a valuable approach for optimizing performance. Furthermore, it is necessary to evaluate psychological state not only on a daily basis but also on a weekly basis based on the previous finding.

When the marathon races were excluded from the data, the coefficients for fatigue, muscle soreness, and Hooper's score were noticeably smaller (Figure 4), indicating that the relationship between TL and psychological state is not proportional. The psychological state value increased markedly at higher TL levels. Moreover, the value tended to remain high despite the low TL one week after the marathon races (Table 2). This suggests that the marathon races, where TL is extremely high, affect the athlete's psychological state over several days. The non-marathon race training volume and intensity of the runner during the race period were low (Figure 3). Thus, even with the marathon races excluded, there is a possibility that a high correlation may be observed between TL and psychological state, depending on the specific characteristics of the runner's training.

Pinot and Grappe (2015) measured the TLquantified using the session RPE method - and performance of a world-class cyclist over a period of six years. They reported that TL increased and the $\mathrm{CV}$ of monotony and strain of training were larger, along with an improvement in performance, indicating a dynamic training model. Takayama et al. (2016b) reported the TL, as quantified by the session RPE method, for a national-level female trail 


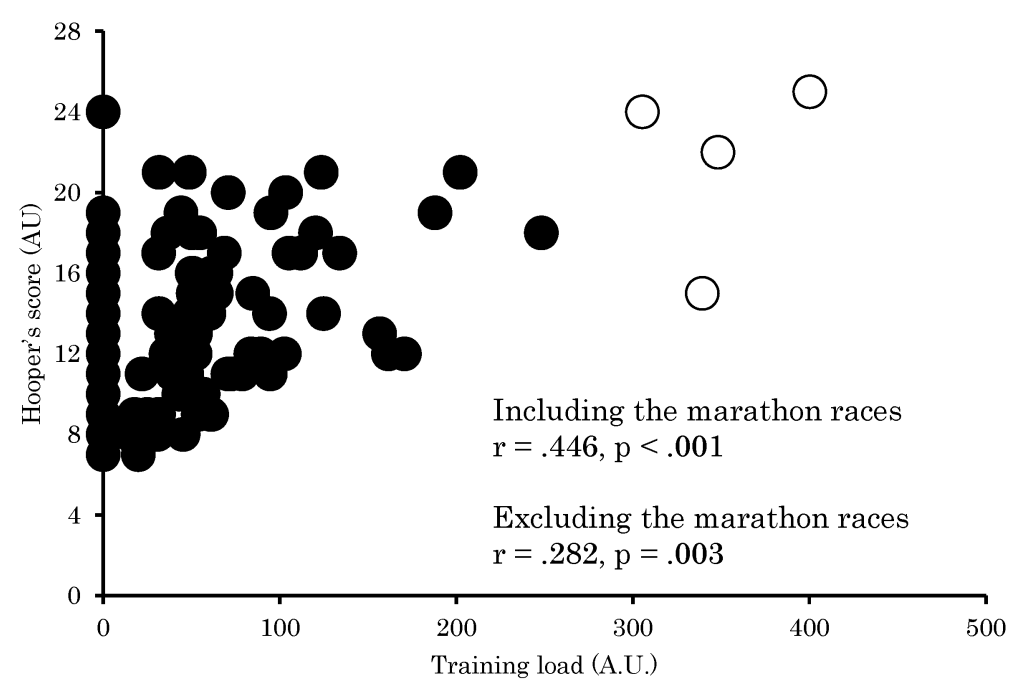

Figure 4 Relationship between daily Training load and Hooper's score.

The training load of the marathon races is indicated by open circle.

runner over a 16-week period. The subject runner participated in four races (a $100 \mathrm{~km}$ ultramarathon race, a $73 \mathrm{~km}$ trail running race, a $37 \mathrm{~km}$ trail running race, and a $77 \mathrm{~km}$ trail running race) during the 16 weeks of observation and performed at a consistently high level-finishing second, second, first, and first. The CV of the TL of the trail runner was $71 \%$, indicating a dynamic model similar to Pinot and Grappe (2015). In the present study, the CV of TL was $46.9 \%$, which was lower than that of the trail runner, but the variation on both a weekly and daily basis was substantial.

According to the training intensity distribution in the present study, the runner's level of intensity was in zone 1 more than $70 \%$ of the time over the 16 week period. In addition, the CV in zone $1(22.6 \%)$ was lower than that in zone $2(108.2 \%)$ or zone 3 $(83.0 \%)$. These results indicate that the runner constantly performed low-intensity training. It has been suggested that sufficient training time at a lowintensity level plays an important role in avoiding overreaching (Seiler et al., 2007). It has also been found that an increase in creatine kinase activity is related to medium-intensity and high-intensity training (Petibois et al., 2002). Indeed, several studies have suggested the importance of low-intensity training for endurance athletes who participate in consecutive races within a short period of time (Metcalfe et al., 2017; Mujika, 2014; Takayama et al., 2018). One such study focused on a runner who participated in 75 races over three years $(38$ road races of marathon distance or less, 18 ultramara- thon races and 19 trail running races) and who performed mostly low-intensity training (Takayama et al., 2018). Another study investigating the year-long training distribution for four professional cyclists showed that the cyclists reduced the intensity and volume of their training in the weeks with no race to try to recover (Metcalfe et al., 2017). In Phase 2 of the present study, the subject runner performed mostly low-intensity training except for the races (Figure 3), and his TL in the weeks with no race tended to be low (Figure 2).

Both the previous research and the present study suggest that a runner who participates in consecutive races within a short period should reduce the intensity and volume of training (except for the races themselves) and that a large variation in TL should be targeted. The characteristics of such training may reduce the variation in the relevant physiological variables as well as performance.

There are several cautionary notes to the present study. First, it is quite possible that participating in multiple races within a short period may produce less than excellent results in any particular race. It is well known that performance improvement is achieved by a tapering that reduces training volume before a race (Mujika and Padilla, 2003). Furthermore, the runner of multiple races should prioritize recovery in the weeks with no race, as it is difficult to train to improve physiological variables and performance with high intensity training or block periodization (Breil et al., 2010). While a low CV of Vmax is evidence that a runner's performance level 
has been recovered, it does not necessarily indicate improvement. However, in the present study, the subject runner set a personal best twice during the experimental period.

Second, a race not only involves high physiological demands; it can cause acute injuries such as pulled muscles, sprains and damage to the soles of a runner's feet. Voight et al. (2011) surveyed 50 runners who had participated in a marathon race one month prior to the survey and reported that $12 \%$ of the respondents had sustained an injury that affected their training program. Although the runner in the present study did not suffer injury after any of his races, runners who run consecutive races within a short period should be aware of the risk of injury, even though physiological variables and performance may be fully recovered.

Finally, the present study is a case study involving a single runner. Further studies should examine the recovery of physiological variables and performance, together with the relationship between TL and psychological state, for runners of different ages, training status, marathon times, and experience. It is also possible that recovery may be affected by factors such as race times and the number of races run, even for the same runner. In the present study, it was difficult to investigate such factors since we did not conduct the treadmill running test after the first marathon race or before and after the second marathon race due to private circumstances of the subject runner.

\section{Conclusions}

This case study investigated the recovery of certain physiological variables and runner performance following marathon races and examined the relationship between TL and psychological state for a runner who participated in multiple consecutive marathon races within a short period of time. The main finding of the study was that variation in performance and in the monitored physiological variables was small. In addition, while there was a significant correlation between TL and stress, fatigue, and muscle soreness, no significant relationship was observed between TL and sleep. Based on these results, TL and the Hooper questionnaire appear to be effective practical tools for monitoring runner training to optimize performance.

\section{References}

Armstrong, S. A., Till, E. S., Maloney, S. R., and Harris, G. A. (2015). Compression socks and functional recovery following marathon running: a randomized controlled trial. J. Strength Cond. Res., 29: 528-533.

Aubry, A., Hausswirth, C., Louis, J., Coutts, A. J., and LE Meur, Y. (2014). Functional overreaching: the key to peak performance during the taper? Med. Sci. Sports Exerc., 46: 1769-1777.

Auersperger, I., Škof, B., Leskošek, B., Knap, B., Jerin, A., Lainščak, M., and Kajtna, T. (2014). Biochemical, hormonal and psychological monitoring of eight weeks endurance running training program in female runners. Kineziologija, 46: 30-39.

Beaver, W. L., Wasserman, K., and Whipp, B. J. (1986). A new method for detecting anaerobic threshold by gas exchange. J. Appl. Physiol., 60: 2020-2027.

Billat, V. L., Petot, H., Landrain, M., Meilland, R., Koralsztein, J. P., and Mille-Harmard, L. (2012). Cardiac output and performance during a marathon race in middle-aged recreational runners. ScientificWorldJournal, 2012: 810859.

Bishop, P. A., Jones, E., and Woods, A. K. (2008). Recovery from training: a brief review: brief review. J. Strength Cond. Res., 22: 1015-1024.

Borg, G. A. (1973). Perceived exertion: a note on "history" and methods. Med. Sci. Sports, 5: 90-93.

Braun, W. A. and Dutto, D. J. (2003). The effect of a single bout of downhill running and ensuing delayed onset of muscle soreness on running economy performed $48 \mathrm{~h}$ later. Eur. J. Appl. Physiol., 90: 29-34.

Breil, F. A., Weber, S. N., Koller, S., Hoppeler, H., and Vogt, M. (2010). Block training periodization in alpine skiing: effects of 11-day HIT on VO2max and performance. Eur. J. Appl. Physiol., 109: 1077-1086.

Buchheit, M., Racinais, S., Bilsborough, J. C., Bourdon, P. C., Voss, S. C., Hocking, J., Cordy, J., Mendez-Villanueva, A., and Coutts, A. J. (2013). Monitoring fitness, fatigue and running performance during a pre-season training camp in elite football players. J. Sci. Med. Sport, 16: 550-555.

Coutts, A., Reaburn, P., Piva, T. J., and Murphy, A. (2007a). Changes in selected biochemical, muscular strength, power, and endurance measures during deliberate overreaching and tapering in rugby league players. Int. J. Sports Med., 28: 116-124.

Coutts, A. J., Wallace, L. K., and Slattery, K. M. (2007b). Monitoring changes in performance, physiology, biochemistry, and psychology during overreaching and recovery in triathletes. Int. J. Sports Med., 28: 125-134.

Faude, O., Kellmann, M., Ammann, T., Schnittker, R., and Meyer, T. (2011). Seasonal changes in stress indicators in high level football. Int. J. Sports Med., 32: 259-265.

Fletcher, J. R., Esau, S. P., and MacIntosh, B. R. (2009). Economy of running: beyond the measurement of oxygen uptake. J. Appl. Physiol., 107: 1918-1922.

Hooper, S. L., Mackinnon, L. T., Howard, A., Gordon, R. D., and Bachmann, A. W. (1995). Markers for monitoring overtraining and recovery. Med. Sci. Sports Exerc., 27: 106-112.

Hopkins, W. G., Marshall, S. W., Batterham, A. M., and Hanin, J. (2009). Progressive statistics for studies in sports medicine and exercise science. Med. Sci. Sports Exerc., 41: 3-13.

Hottenrott, K., Ludyga, S., Schulze, S., Gronwald, T., and 
Jäger, F. S. (2016). Does a run/walk strategy decrease cardiac stress during a marathon in non-elite runners? J. Sci. Med. Sport, 19: 64-68.

Kobayashi, Y., Takeuchi, T., Hosoi, T., Yoshizaki, H., and Loeppky, J. A. (2005). Effect of a marathon run on serum lipoproteins, creatine kinase, and lactate dehydrogenase in recreational runners. Res. Q. Exerc. Sport, 76: 450-455.

Krustrup, P., Ortenblad, N., Nielsen, J., Nybo, L., Gunnarsson, T. P., Iaia, F. M., Madsen, K., Stephens, F., Greenhaff, P., and Bangsbo, J. (2011). Maximal voluntary contraction force, SR function and glycogen resynthesis during the first $72 \mathrm{~h}$ after a high-level competitive soccer game. Eur. J. Appl. Physiol., 111: 2987-2995.

Kyröläinen, H., Pullinen, T., Candau, R., Avela, J., Huttunen, P., and Komi, P. V. (2000). Effects of marathon running on running economy and kinematics. Eur. J. Appl. Physiol., 82: 297-304.

Lourenço, T. F., Martins, L. E., Tessutti, L. S., Brenzikofer, R., and Macedo, D. V. (2011). Reproducibility of an incremental treadmill VO2max test with gas exchange analysis for runners. J. Strength Cond. Res., 25: 1994-1999.

Lucía, A., Hoyos, J., Pérez, M., and Chicharro, J. L. (2000). Heart rate and performance parameters in elite cyclists: a longitudinal study. Med. Sci. Sports Exerc., 32: 1777-1782.

Marcora, S. M. and Bosio, A. (2007). Effect of exercise-induced muscle damage on endurance performance in humans. Scand. J. Med. Sci. Sports, 17: 662-671.

Metcalfe, A. J., Menaspà, P., Villerius, V., Quod, M., Peiffer, J. J., Govus, A. D., and Abbiss, C. R. (2017). The withinseason distribution of external training and racing worldload in professional male road cyclist. Int. J. Sports Physiol. Perform., 12: S2142-S2146.

Moalla, W., Fessi, M. S., Farhat, F., Nouira, S., Wong, D. P., and Dupont, G. (2016). Relationship between daily training load and psychometric status of professional soccer players. Res. Sports Med., 24: 387-394.

Mujika, I. (2014). Olympic preparation of a world-class female triathlete. Int. J. Sports Phsiol. Perform., 9: 727-731.

Mujika, I. and Padilla, S. (2003). Scientific bases for precompetition tapering strategies. Med. Sci. Sports Exerc., 35: 1182-1187.

Muñoz, I., Seiler, S., Bautista, J., España, J., Larumbe, E., and Esteve-Lanao, J. (2014). Does polarized training improve performance in recreational runners? Int. J. Sports Physiol. Perform., 9: 265-272.

Neal, C. M., Hunter, A. M., and Galloway, S. D. (2011). A 6month analysis of training-intensity distribution and physiological adaptations in ironman triahtltes. J. Sports Sci., 29: 1515-1523.

Nédélec, M., Halson, S., Abaidia, A. E., Ahmaidi, S., and Dupont, G. (2015). Stress, sleep and recovery in elite soccer: a critical review of the literature. Sports Med., 45: 1387-1400.

Nedelec, M., McCall, A., Carling, C., Legall, F., Berthoin, S., and Dupont, G. (2014). The influence of soccer playing actions on the recovery kinetics after a soccer match. J. Strength Cond. Res., 28: 1517-1523.

Neilan, T. G., Yoerger, D. M., Douglas, P. S., Marshall, J. E., Halpern, E. F., Lawlor, D., Picard, M. H., and Wood, M. J. (2006). Persistent and reversible cardiac dysfunction among amateur marathon runners. Eur. Heart J., 27: 1079-1084.

Noakes, T. D., Myburgh, K. H., and Schall, R. (1990). Peak treadmill running velocity during the $\mathrm{VO} 2$ max test predicts running performance. J. Sports Sci., 8: 35-45.

Nunes, J. A., Moreira, A., Crewther, B. T., Nosaka, K., Viveiros, L., and Aoki, M. S. (2014). Monitoring training load, recovery-stress state, immune-endocrine responses, and physical performance in elite female basketball players during a periodized training program. J. strength Cond. Res., 28: 2973-2980.

Onodera, K. and Miyashita, M. (1976). A study on Japanese Scale for rating of perceived exertion in endurance exercise. Jpn. J. Phys. Educ. Health Sport Sci., 21: 191-203. (in Japanese).

Petibois, C., Cazorla, C., Poortmans, J. R., and Deleris, G. (2002). Biochemical aspects of overtraining in endurance sports: a review. Sports Med., 32: 867-878.

Pinot, J. and Grappe, F. (2015). A six-year monitoring case study of a top-10 cycling grand tour finisher. J. Sports Sci., 33: $907-914$

Plews, D. J., Laursen, P. B., Kilding, A. E., and Buchheit, M. (2012). Heart rate variability in elite triathletes, is variation in variability the key to effective training? A case comparison. Eur. J. Appl. Physiol., 112: 3729-3741.

Saunders, P. U., Cox, A. J., Hopkins, W. G., and Pyne, D. B. (2010). Physiological measures tracking seasonal changes in peak running speed. Int. J. Sports Physiol. Perform., 5: 230-238.

Seiler, S., Haugen, O., and Kuffel, E. (2007). Autonomic recovery after exercise in trained athletes: intensity and duration effects. Med. Sci. Sports Exerc., 39: 1366-1373.

Solberg, G., Robstad, B., Skjønsberg, O. H., and Borchsenius, F. (2005). Respiratory gas exchange indices for estimating the anaerobic threshold. J. Sports Sci. Med., 4: 29-36.

Sylta, O., Tønnessen, E., and Seiler, S. (2014). From heart-rate data to training quantification: a comparison of 3 methods of training-intensity analysis. Int. J. Sports Physiol. Perform., 9: 100-107.

Takayama, F., Aoyagi, A., Shimazu, W., and Nabekura, Y. (2017a). Effects of marathon running on aerobic fitness and performance in recreational runners one week after a race. $\mathrm{J}$. Sports Med., 2017: 9402386.

Takayama, F., Hirata, K., Mori, H., Nabekura, Y., and Miyamoto, N. (2016a). Daigakusei simin runner no marathon race ga kinsonsyosihyo to yuusannsoseinouryoku ni ataeru eikyo [Effects of a marathon race on muscle damage markers and aerobic fitness in college recreational runners]. J. Running Sci., 27: 47-58. (in Japanese).

Takayama, F., Hirata, K., Nabekura, Y., Kanehisa, H., and Miyamoto, N. (2017b). Effects of marathon running on muscle damage in lower limb muscle groups and maximal aerobic capacity in novice recreational runners. Gazz. Med. Ital., 176: 100-109.

Takayama, F., Miyazaki, K., and Yamamoto, M. (2016b). Training and pace strategy of a women's trail runner: the winner in a 76.7-km trail running race. Res. J. Sports Perform., 8: 180-198. (in Japanse).

Takayama, F., Tsuji, T., Aoyagi, A., and Nabekura, Y. (2018). Recovery of physiological characteristics and muscle soreness after a marathon running in a well-trained runner: a case study. Gazz. Med. Ital., 177: 46-50.

Tojima, M., Noma, K., and Torii, S. (2016). Changes in serum creatine kinase, leg muscle tightness, and delayed onset muscle soreness after a full marathon race. J. Sports Med. Phys. Fitness, 56: 782-788.

Twist, C. and Highton, J. (2013). Monitoring fatigue and 
recovery in rugby league players. Int. J. Sports Physiol. perform., 8: 467-474.

Voight, A. M., Roberts, W. O., Lunos, S., and Chow, L. S. (2011). Pre- and postmarathon training habits of nonelite runners. Open Access J. Sports Med., 3: 13-18.

Zouhal, H., Jacob, C., Groussard, C., Moussa, E., Delamarche, P., and Gratas-Delamarche, A. (2006). Effect of marathon running on aerobic performances in highly trained athletes. Science and Sports, 21: 303-305. (in French).

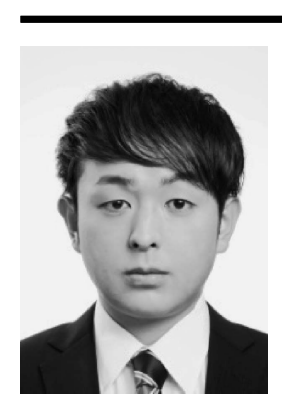

Name:

Fuminori Takayama

Affiliation:

Faculty of Health and Sport Sciences, University of Tsukuba

Research Fellow of Japan Society for the Promotion of Science

Address:

1-1-1 Tennodai, Tsukuba-shi, Ibaraki 305-8574, Japan

Brief Biographical History:

Fuminori Takayama is the research fellowship for young scientists of Japan society for the promotion of Science. He obtained Ph.D. at University of Tsukuba in 2018.

Main work:

-Takayama, F., Aoyagi, A., Shimazu, W., and Nabekura, Y. (2017). Effects of marathon running on aerobic fitness and performance in recreational runners one week after a race. J. Sports Med., 2017: 9402386.

-Takayama, F., Aoyagi, A., Takahashi, K., and Nabekura, Y. (2018). Relationship between oxygen cost and C-reactive protein response to marathon running in college recreational runners. Open Access J. Sports Med., 9: 261-268.

Membership in learned Societies:

-European College of Sport Science

- Japanese Society of Physical Fitness and Sports Medicine

-Japan Society of Physical Education, Health and Sport Sciences

- Society for Running 